\title{
Gilaburu Bitkisinin (Viburnum opulus L.) Meyve, Sap ve Yaprağının Mineral İçeriği Onur TAŞKIN ${ }^{\infty}$ (D), Barış Bülent AŞIK ${ }^{2}$ (D), Nazmi IZLLI ${ }^{3}$ (D), \\ ${ }^{1,3}$ Bursa Uludağ Üniversitesi, Ziraat Fakültesi, Biyosistem Mühendisliği Bölümü, Bursa ${ }^{2}$ Bursa Uludağ Üniversitesi, Ziraat Fakültesi, Toprak \\ Bilimi ve Bitki Besleme Bölümü, Bursa \\ ${ }^{1}$ https://orcid.org/0000-0002-5741-8841, ${ }^{2}$ https://orcid.org/0000-0001-8395-6283, ${ }^{3}$ https://orcid.org/0000-0002-2084-4660 \\ 凶: onurtaskins@gmail.com
}

\section{ÖZET}

Bu çalışmada, doğada organik olarak yetişen gilaburunun meyve, sap ve yapraklarının mineral madde ve protein içerikleri araştırılmıştır. Gilaburu meyve, sap ve yapraklarının makro element içerikleri sirasiyla \%0.52-0.51-1.94 Azot (N), \%0.09-0.04-0.42 Fosfor (P), \%0.930.10-1.17 Potasyum (K), \%0.21-0.48-2.44 Kalsiyum (Ca), \%0.05-0.040.37 Magnezyum $(\mathrm{Mg})$ ve \%0.04-0.06-0.09 Sodyum $(\mathrm{Na})$ olarak tespit edilmiştir. Mikro elementleri ise 12.81-215.83-436.35 $\mathrm{mg} \mathrm{kg}^{-1}$ Demir (Fe), 5.69-12.38-8.05 mg kg-1 Bakır (Cu), 6.45-19.97-25.81 $\mathrm{mg} \mathrm{kg}^{-1}$ Çinko (Zn) ve $1.56-26.62-40.47 \mathrm{mg} \mathrm{kg}{ }^{-1}$ Mangan (Mn) olarak bulunmuştur. Meyve, sap ve yaprakların protein sonuçları ise sırasıyla \%0.52, \%0.51 ve \%12.10 olarak belirlenmiştir. Sonuçlar yapraklardaki protein ve mineral madde içeriklerinin (Bakır hariç) meyve ve saptan daha yüksek olduğunu ve yaprakların alternatif değerlendirme olanaklarının araştırılması gerektiğini ortaya koymaktadır.
Araştırma Makalesi

Makale Tarihçesi

Geliş Tarihi : 16.11 .2018

Kabul Tarihi : 24.12 .2018

Anahtar Kelimeler

Viburnum Opulus L.

Element

Protein

\section{Mineral Content of Leaves, Stalks and Fruits of European Cranberrybush Plant (Viburnum opulus L.)}

\section{ABSTRACT}

In this study, the protein and mineral contents of fruit, stalks and leaves of naturally grown European Cranberrybush were investigated. The macro element contents of European Cranberrybush fruits, stalks and leaves were determined as $0.52-0.51-1.94 \%$ Nitrogen $(\mathrm{N})$, 0.09-0.04-0.42\% Phosphorus (P), 0.93-0.10-1.17\%, Potassium (K), 0.21-0.48-2.44\% Calcium (Ca), 0.05-0.04-0.37\% Magnesium (Mg) and 0.04-0.06-0.09\% Sodium $(\mathrm{Na})$, respectively. The micro elements were found 12.81-215.83-436.35 mg kg-1 Iron ( $\mathrm{Fe}$ ), 5.69-12.38-8.05 mg kg-1 Copper (Cu), 6.45-19.97-25.81 mg kg-1 Zinc (Zn) and 1.56-26.62-40.47 $\mathrm{mg} \mathrm{kg}{ }^{-1}$ Mangan (Mn), respectively. Protein results of fruits, stalks and leaves were determined as $0.52 \%, 0.51 \%$ and $12.10 \%$, respectively. The results showed that the protein and mineral contents of the leaves (except copper) were higher than the fruit and the leaves, and the alternative evaluation possibilities of leaves should be investigated.

\section{Research Article}

$\begin{array}{ll}\text { Article History } & \\ \text { Received } & : 16.11 .2018 \\ \text { Accepted } & : 24.12 .2018\end{array}$

\section{Keywords}

Viburnum Opulus L.

Eleman

Protein

To Cite : Taşkın O, Aşık BB, İzli N 2019. Gilaburu Bitkisinin (Viburnum opulus L.) Meyve, Sap ve Yaprağının Mineral : İçeriği. KSÜ Tar Doğa Derg 22(2): 178-182, DOI : 10.18016/ksutarimdoga.vi.484362

\section{GİİŞ}

Viburnum L. cinsi Türkiye'de dört tür ile temsil edilir ve "gilaburu, giraoğlu, giligili, dağdağan, dağdığan, geleboru, gilabada, gildar" isimleri ile bilinmektedir (Ecevit-Genç ve Yıldırım, 2018). Dikiminden 3 yıl sonra meyve vermeye başlayabilen ve hızla büyüyerek dip sürgünleri sayesinde 300 yıl kadar yaşayabilen çok yıllık bir bitkidir. Aynı kökten gelen gövdelerin bir arada dallanması ile dik çalı ya da ağaç formuna geçmekte ve boyu 4 metreye kadar ulaşabilmektedir. Periyodisite durumu göstermeyen bitkiden her yıl aynı oranda verim alınabilmektedir. Bitkinin meyve tutma oranı \%15.32 ve bitki başına verimi $8.4 \mathrm{~kg}$ civarıdır.
Kaliteli meyve için organik maddelerce zengin toprak, bol miktarda su ve güneş ışığına ihtiyaç duymaktadır (Koca, 2009).

Bitkinin sarımsı beyaz renkli çiçekleri Nisan ayında açar. Çiçek demetinin dış kısmında bir sıra steril (kısır), iç kısmındaki fertil (döllenebilir) çiçekler bulunur (Konarska, 2017) ve böcekler tarafından tozlaştırılır. Nisan ayı sonunda tozlaşan çiçekler yerini küçük yeşil renkli meyvelere bırakır. Haziran ayında ise bu meyveler kızarmaya başlar. Olgunlaşan meyveler; yuvarlak ve salkım şeklindedir. Her bir meyve tanesinin çapı $0.8-1 \mathrm{~cm}$, dane ağırlıkları ise 0.45-0.64 gr arasında değişmekte ve içerisinde tek 
çekirdek bulunmaktadır. Yaprakları karşılıklı olacak şekilde çapraz, kenarları dişli, 3-5 loplu, 3 damarlı, 5$10 \mathrm{~cm}$ uzunluğunda ve geniş şekillidir. İlkbaharda yeşil olan yapraklar sonbahara doğru açık kırmızı bir renk almaktadır (Zarifikhosroshahi, 2015).

İçinde bulunduğumuz yüzyılda artan nüfus artışı nedeniyle özellikle doğal olarak bulunan, insan sağllğ̆ ve beslenme açısından büyük öneme sahip meyve türlerinin değerlendirilmesini zorunlu kllmaktadır. Günümüzde gilaburunun farmakoloji (Boyacı ve ark., 2016), meyve suyu, nektar (Çam ve Hisil, 2007), reçel, marmelat (Rop ve ark., 2010) turşu, sirke, gida takviyesi (tablet) ve çay gibi geniş kullanım alanları bulunmaktadır. Önemi her geçen gün artan gilaburu meyvesinin mineral içeriğiyle ilgili ulaşılabilen ilk araştırma Bolat ve Özcan (1995) tarafindan yapılmıştır. Ancak, son ylllarda ise tıbbi etkileri üzerine bilimsel çalışmalar artmıştır. Kolon kanseri (Ulger ve ark., 2013), böbrek taşı (İlhan ve ark., 2014; Tuğlu ve ark., 2014), jinekolojik bozukluk (Saltan ve ark., 2016), testis ve sperm hasarının hafifletmesi (Sarıözkan ve ark., 2017) ve antikanser etkisi (Ceylan ve ark., 2018) gibi birçok çalışmada faydaları bilimsel olarak da ispatlanmıştır. Bu çalışma kapsamında doğada organik olarak yetişen gilaburunun yaprak, sap ve meyvelerinin mineral ve protein içerikleri bakımından karşılaştırılması amaçlanmıştır.

\section{MATERYAL ve METOT}

\section{Materyal}

Deneylerde kullanılan gilaburu örnekleri (meyve, sap ve yaprak) Kayseri ili Sarız ilçesi Çörekdere mahallesinde yerel bir üreticiden temin edilmiştir (Şekil 1). Bahçe $\left(38^{\circ} 28^{\prime} 49.76^{\prime \prime}\right.$ kuzey enlemi ve $36^{\circ} 27^{\prime} 54.96^{\prime \prime}$ doğu boylamı) Kayseri il merkezinin $125.5 \mathrm{~km}$ güneydoğusunda ve deniz seviyesinden 1597 m. yüksekliğindedir. Karasal iklim koşulları özelliklerini taşıyan bölge İç Anadolu, Doğu Anadolu ve Akdeniz Bölgelerinin kesiştiği noktada bulunmaktadir.

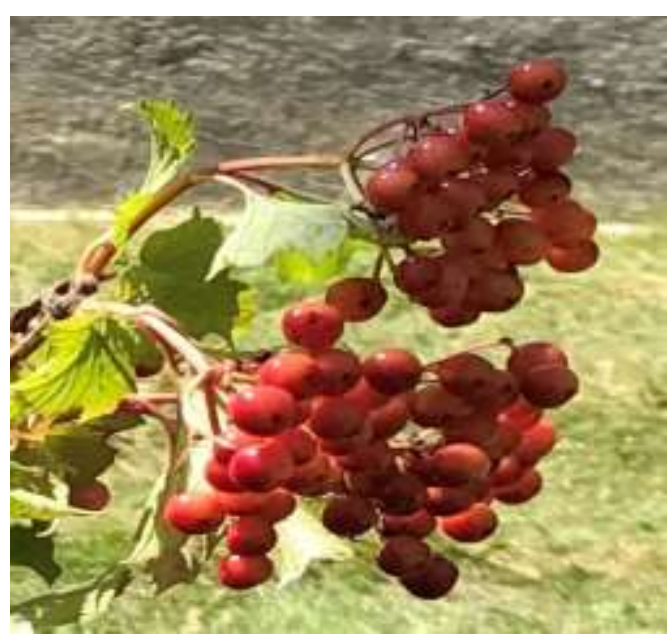

Şekil 1. Gilaburu örnekleri
Elde edilen örnekler deneyler süresince $4 \pm 0.5{ }^{\circ} \mathrm{C}$ sıcaklık koşullarında muhafaza edilmiştir. Numuneler $105{ }^{\circ} \mathrm{C}$ sicaklıktaki etüvde (ED115 Binder, Tuttlingen, Almanya) 24 saat süre ile kurutulmuştur (Taşkın ve ark., 2018).

\section{Mineral İçeriğinin Belirlenmesi}

Elementlerin toplam konsantrasyonları 0.20-0.50 gr örneğin mikrodalga firında (MWS 2 DAP 60K, Berghof, Almanya) $4 \mathrm{~mL} \mathrm{HNO}_{3}$ ve $3 \mathrm{~mL} \mathrm{H}_{2} \mathrm{O}_{2}$ ile yaş yakılması sonucu elde edilmiştir. Sodyum (Na), Potasyum (K) ve Kalsiyum (Ca) elementleri flame emisyon metodu kullanılarak flame fotometresinde (6361, Eppendorf Elex, Almanya) belirlenmiştir (Horneck ve Hanson, 1998). Fosfor (P), Magnezyum $(\mathrm{Mg})$, Demir $(\mathrm{Fe})$, Bakır $(\mathrm{Cu})$, Çinko ( $\mathrm{Zn})$ ve Mangan (Mn) elementleri ise indüktif olarak eşleşmiş plazma optik emisyon spektrometresi (ICP-OES) (Optima 2100 DV, Perkin Elmer, ABD) kullanılarak tespit edilmiştir (Isaac ve Johnson, 1998).

\section{Protein İçeriğinin Belirlenmesi}

Örneklerin protein içeriklerinin belirlenmesinde modifiye edilmiş Kjeldahl yöntemi kullanılmıştır. Sülfirik asit ve katalizör $\left(\mathrm{K}_{2} \mathrm{SO}_{4}+\mathrm{CuSO}_{4}+\mathrm{Se}\right)$ ile yakma setinde (K-437, Buchi, İsviçre) yakılan örnekler alkali ortamda damıtılmıştır (K-350, Buchi, İsviçre). Ortaya çıkan amonyak $\left(\mathrm{NH}_{4}\right)$ miktarı sülfirik asitle titre edilerek azot miktarı ölçülmüştür. Elde edilen sonuçlar 6.25 faktörü ile çarpılarak örneklerin protein miktarı hesaplanmıştır (Bremmer, 1965).

\section{İstatistiksel Değerlendirme}

Çalışma kapsamında yapılan tüm denemeler üç tekrarlı olarak gerçekleştirilmiştir. Elde edilen veriler JMP programı (Versiyon 7.0, ABD) ile Asgari Önemli Farklılık (LSD) çoklu karşılaştırma testi $(\mathrm{p}<0.05)$ kullanılarak analiz edilmiştir.

\section{BULGULAR ve TARTIŞMA}

Gilaburu meyvesinin makro elementleri \%0.52 Azot $(\mathrm{N})$, \%0.09 Fosfor (P), \%0.93 Potasyum (K), \%0.21 Kalsiyum (Ca), \%0.05 Magnezyum (Mg) ve \%0.04 Sodyum (Na) olarak bulunmuştur (Şekil 2). Mikro elementler ise $12.81 \mathrm{mg} \mathrm{kg}^{-1}$ Demir $(\mathrm{Fe}), 5.69 \mathrm{mg} \mathrm{kg}^{-1}$ Bakır (Cu), $6.45 \mathrm{mg} \mathrm{kg}^{-1}$ Çinko $(\mathrm{Zn})$ ve $1.56 \mathrm{mg} \mathrm{kg}^{-1}$ Mangan (Mn) olarak tespit edilmiştir (Şekil 3). Gilaburu meyvesinin makro ve mikro elementler açısından Azot $(\mathrm{N})$, Demir ( $\mathrm{Fe}$ ) içeriği en zengin ve Sodyum (Na), Mangan (Mn) en kisitl olarak bulunmuştur. Özrenk ve ark. (2011) Erzincan ili Konakbaşı ve Kılıçkaya köylerinden temin ettikleri gilaburu meyvesinin bazı fiziksel ve kimyasal özellikleri üzerine araştırmalar yapmışlardır.

Mineral element analizleri sonucunda Fosfor (P), Potasyum (K), Kalsiyum (Ca) ve Mangan ( $\mathrm{Mg}$ ) makro 
elementlerinin Konakçıbaşı köyü örnekleri için sirasıyla 1663, 2970, 1856 ve 1340 ppm olduğunu, Kılıçkaya köyü örnekleri için ise 1300, 2680, 1752 ve 1190 ppm olduğunu belirlemişlerdir.

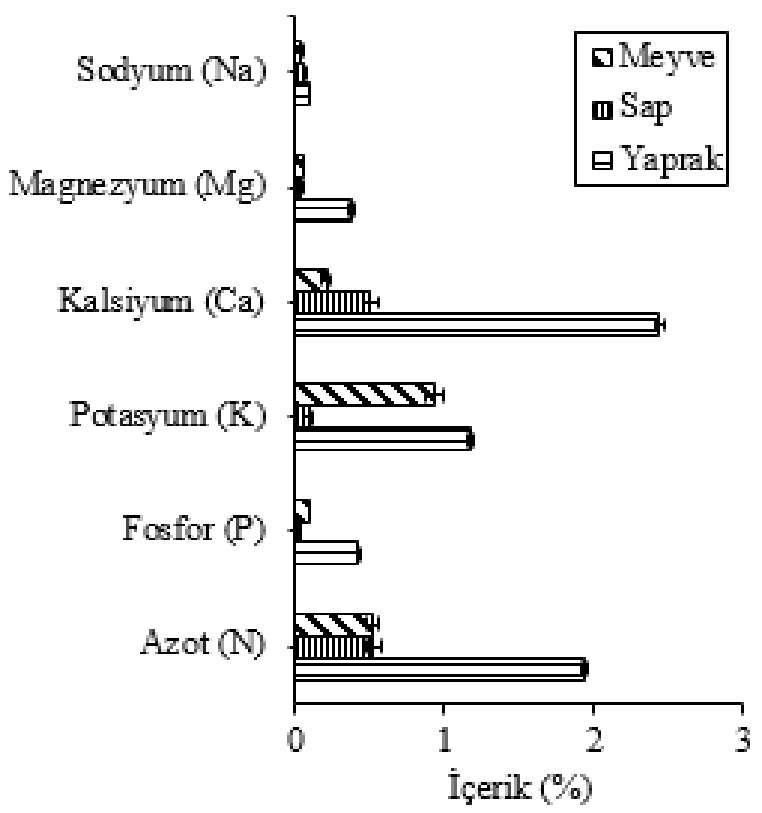

Şekil 2. Makro element içerik sonuçları (\%)

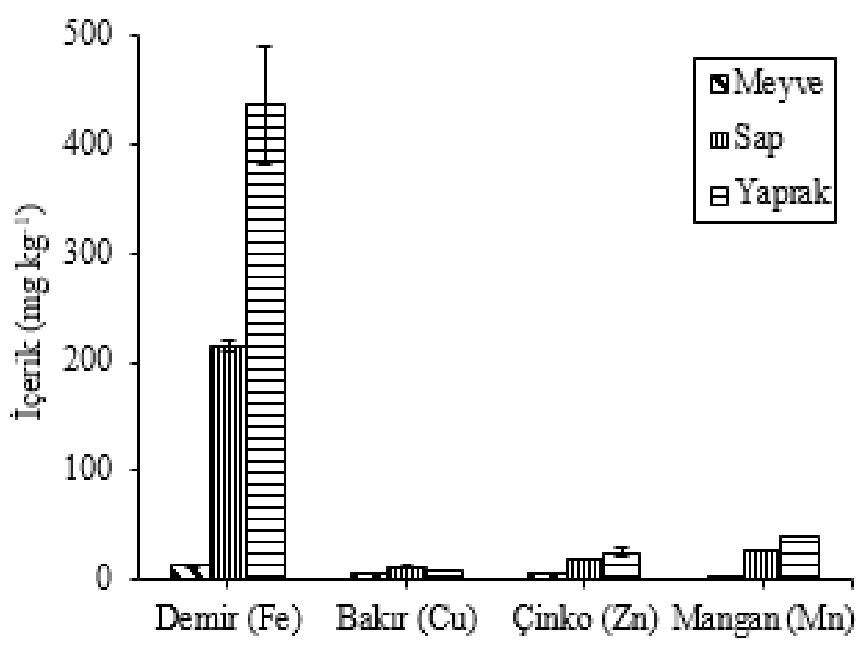

Şekil 3. Mikro element içerik sonuçları ( $\left.\mathrm{mg} \mathrm{kg}^{-1}\right)$

Gilaburu meyvesinin mikro element analizleri sonucunda Konakçıbaşı köyü örnekleri için 2.9 ppm Demir (Fe), 1.6 ppm Çinko (Zn), 1.7 ppm Bakır $(\mathrm{Cu})$ ve 0.6 ppm Mangan (Mn), Kılıçkaya köyü örnekleri için ise 2.1 ppm Demir (Fe), 1.7 ppm Çinko (Zn), 1.5 Bakır $(\mathrm{Cu})$ ve $0.5 \mathrm{ppm}$ Mangan bulundurduğunu tespit etmişlerdir. Akbulut ve ark. (2008) Kayseri ili Gömeç mahallesinden edindikleri gilaburu meyvesinin mineral içeriğinde Alüminyum (Al) 7.67 ppm, Bor (B) 40.47 ppm, Baryum (Ba) 6.45 ppm, Kalsiyum (Ca) 2441 ppm, Kobalt (Co) 0.31 ppm, Krom (Cr) 0.49 ppm, Bakır (Cu) 5.58 ppm, Demir (Fe) 15.46 ppm, Potasyum (K)
8420 ppm, Lityum (Li) 0.70 ppm, Magnezyum (Mg) 900 ppm, Mangan (Mn) 2.59 ppm, Sodyum (Na) 345.3 ppm, Nikel (Ni) 1.43 ppm, Fosfor (P) 607.5 ppm, Kükürt (S) $526.1 \mathrm{ppm}$, Stronsiyum (Sr) $8.63 \mathrm{ppm}$ ve Çinko ( $\mathrm{Zn}$ ) 11.75 ppm olarak bulmuşlardır. Kalyoncu ve ark. (2013) Gilaburu meyvesindeki 27 farklı minerali analiz etmişlerdir. Sirasıyla K (10764.76 ppm), Mg (1289.09 ppm), P (1304.17 ppm), Fe (17.14 ppm), Ca (1228.71 ppm), Mn (2.42 ppm), Z (1.54 ppm), Al (12.56 ppm), Na (25.70 ppm), Cu (2.99 ppm), Li (1.37 ppm), $\mathrm{Ba}$ (5.18 ppm), Sr (8.49 ppm), S (421.59 ppm), B (12.30 $\mathrm{ppm}), \mathrm{V}(3.45 \mathrm{ppm})$ ve $\mathrm{Cr}(1.42 \mathrm{ppm})$ sonuçlarını bulmuşlardır. Se, $\mathrm{Ni}, \mathrm{Pb}$ ve $\mathrm{Cd}$ ise iz element olarak tespit belirlenmiştir. Zarifikhosroshahi (2015) Dört farklı lokasyonda (Ardahan, Kayseri, Sivas ve Gümüşhane) yetişen gilaburu meyvelerindeki besin element konsantrasyonlarını tespit etmiştir. Sırasıyla en yüksek makro element ( $\mathrm{P}, \mathrm{K}, \mathrm{Mg}, \mathrm{Ca}$ ve $\mathrm{N}$ ) ve mikro element $(\mathrm{Cu}, \mathrm{Mn}, \mathrm{Fe}$ ve $\mathrm{Zn})$ değerleri Gümüşhane (\% 1.43), Ardahan (\% 1.02), Kayseri (\%0.065), Sivas (\%0.36), Gümüşhane (\% 0.93), Gümüşhane (1.53 ppm), Kayseri (28.04 ppm), Ardahan (43.13 ppm) ve Sivas (23.80 ppm) olarak bulunmuştur.

Gilaburu meyvesinin sapı üzerinde yapılan analizler sonucunda; makro elementler \%0.51 Azot (N), \%0.04 Fosfor (P), \%0.10 Potasyum (K), \%0.48 Kalsiyum (Ca), $\% 0.04$ Magnezyum $(\mathrm{Mg})$ ve \%0.06 Sodyum $(\mathrm{Na})$ olarak belirlenmiştir (Şekil 2). Mikro elementler ise 215.83 $\mathrm{mg} \mathrm{kg}^{-1}$ Demir (Fe), $12.38 \mathrm{mg} \mathrm{kg}^{-1}$ Bakır (Cu), $19.97 \mathrm{mg}$ $\mathrm{kg}^{-1}$ Çinko (Zn) ve $26.62 \mathrm{mg} \mathrm{kg}^{-1}$ Mangan (Mn) olarak bulunmuştur (Şekil 3). Bitkinin yapraklarında ise makro elementler \%1.94 Azot (N), \%0.42 Fosfor (P), \%1.17 Potasyum (K), \%2.44 Kalsiyum (Ca), \%0.37 Magnezyum $(\mathrm{Mg})$ ve \%0.09 Sodyum $(\mathrm{Na})$ ve mikro elementler $436.35 \mathrm{mg} \mathrm{kg}^{-1}$ Demir (Fe), $8.05 \mathrm{mg} \mathrm{kg}^{-1}$ Bakır (Cu), $25.81 \mathrm{mg} \mathrm{kg}^{-1}$ Çinko (Zn) ve $40.47 \mathrm{mg} \mathrm{kg}^{-1}$ Mangan (Mn) olarak tespit edilmiştir. Burnaz ve ark. (2010) gilaburu meyvesinin suyu, zarı, çekirdek, yaprak ve dalında $0.20-23134 \mathrm{mg} \mathrm{kg}^{-1}$ aralığında $\mathrm{Fe}$, $\mathrm{Cu}, \mathrm{Mn}, \mathrm{Zn}, \mathrm{Na}, \mathrm{K}$, Ca ve $\mathrm{Mg}$ elementlerini olduğunu belirlemiştir.

Yapılan protein analizleri ile meyve, sap ve yaprak sonuçları sırasıyla $\% 0.52, \% 0.51$ ve $\% 12.10$ olarak bulunmuştur. İstatistiksel analizde meyve ile sap arasındaki farkın önemsiz olduğu belirlenmiştir $(\mathrm{p}<0.05)$. Kalyoncu ve ark. (2013) gilaburu meyvesinde yaptıkları bir araştırmada protein değerini \%0.2 olarak bulmuşlardır. Akbulut ve ark. (2008) ise gilaburu meyvesinin protein analizini yapmış ve $\% 6.48$ olarak tespit etmişlerdir. Sonuçlar gilaburunun farklı protein içeriğine sahip olduğunu göstermiştir. Gilaburunun protein içeriğindeki bu farklılıklar; yetiştirme koşullarına, çeşit, genetik faktörler, hasat zamanı, toprak yapısı ve coğrafi değişkenliklere bağlı olabilmektedir (Er ve Özcan, 2010). 


\section{SONUÇ}

$\mathrm{Bu}$ çalışma ile Kayseri bölgesinde organik olarak yetişen gilaburunun meyve, sap ve yapraklarının insan sağllğ̣ ve beslenmesinde önemli rol oynayan bazı mineral madde ve protein içerikleri belirlenmiştir. Yapraklarında tüm element düzeylerinin (Bakır hariç) meyve ve sapına göre daha yüksek düzeyde bulunmuştur ve yaprakların beslenme amaçlı değerlendirme olanaklarının araştırılması gerekli kılınmaktadır.

$\mathrm{Bu}$ araştırma sonucunda Türkiye'de coğrafi işareti alınmış olan bu bitkinin alternatif değerlendirme yöntemlerinin belirlenmesine yön verebilecek veriler ortaya konmuştur. Ayrıca ıslah yoluyla geliştirilmesi, ekiminin yaygınlaştırılması, hasat öncesi ve sonrası çalışmalarının önemini ortaya koymaktadır.

\section{KAYNAKLAR}

Akbulut M, Calisir S, Marakoglu T, Coklar H 2008. Chemical and Technological Properties of European Cranberrybush (Viburnum Opulus L.) Fruits. Asian Journal of Chemistry, 20(3): 1875-1885.

Bolat S, Özcan M 1995. Gilaburu (Viburnum opulus L.) Meyvesinin Morfolojik, Fenolojik ve Pomolojik Özellikleri ile Kimyasal Bileşimi. Türkiye II. Ulusal Bahçe Bitkileri Kongresi, 13-16 Ekim, Adana.

Boyacı H, Çöteli E, Karataş F 2016. Gilaburu (Viburnum opulus L.) Meyvesindeki A, E Vitamini, Beta-Karoten, Likopen, Redükte ve Okside Glutatyon Miktarlarının Araştırılması. Erzincan Üniversitesi Fen Bilimleri Enstitüsü Dergisi, 9(2): 111-117.

Burnaz NA, Koz M, Demir A, Şen İU, İskefiyeli Z, Baltaş N, Aktaş A, Gündoğdu A, Duran C, Ertürk Ö, Küçük M 2010. Gilaburu Meyvesinin Özütlerinin Mineral Bileşimi ve Biyolojik Aktiviteleri. 24. Ulusal Kimya Kongresi, 2 Temmuz, Zonguldak.

Bremmer JM 1965. American Society of Agronomy, Part 2, Inc. Pub. Agronomy Series, Madison, WI, s. 1149-1178.

Ceylan D, Aksoy A, Ertekin T, Yay AH, Nisari M, Karatoprak GŞ, Ülger H 2018. The Effects of Gilaburu (Viburnum opulus) Juice on Experimentally Induced Ehrlich Ascites Tumor in Mice. Journal of Cancer Research and Therapeutics, 14(2): 314-320.

Çam M, Hisil Y 2007. Comparison of Chemical Characteristics of Fresh and Pasteurised Juice Of Gilaburu (Viburnum opulus L.). Acta Alimentaria, 36: 381-385.

Ecevit-Genç G, Yıldırım HN 2018. Leaf and Petiole Anatomy of Viburnum opulus L. (Adoxaceae). Erzincan Üniversitesi Fen Bilimleri Enstitüsü Dergisi, 11(1): 102-106.

Er F, Özcan MM 2010. Chemical Compositional
Properties and Mineral Contents of Some Apple Cultivars. South-Western Journal of Horticulture Biology and Environment, 1(2): 121-131.

Horneck DA, Hanson D 1998. Handbook of Reference Methods for Plant Analysis. CRC Pres. Washington, D.C, s. 157-164.

Isaac AR, Johnson WC 1998. Handbook of Reference Methods for Plant Analysis. CRC Pres. Washington, D.C, s. 65-170.

İlhan M, Ergene B, Süntar I, Özbilgin S, Saltan Çitoğlu G, Demirel MA, Keleş H, Altun L, Küpeli Akkol E. 2014. Preclinical Evaluation of Antiurolithiatic Activity of Viburnum opulus L. on Sodium Oxalate-induced Urolithiasis Rat Model. Evidence-Based Complementary and Alternative Medicine, 1-7.

Kalyoncu IH, Ersoy N, Elidemir AY, Karali ME 2013. Some Physico-Chemical Characteristics and Mineral Contents of Gilaburu (Viburnum opulus L.) Fruits in Turkey. International Scholarly and Scientific Research \& Innovation, 7(6): 424-426.

Koca S 2009. Kayseri İlinde Gilaboru Bitkisi (Viburnum Opulus L.) Üzerinde Bulunan Arthropoda Türlerinin Belirlenmesi. Selçuk Üniversitesi Fen Bilimleri Enstitüsü Bitki Koruma Anabilim Dalı, Yüksek Lisans Tezi. 62 s.

Konarska A 2017. Comparative Micromorphology and Anatomy of Flowers and Floral Secretory Structures in Two Viburnum Species. Protoplasma, 254(1): 523-537.

Özrenk K, Gündoğdu M, Keskin N, Kaya T 2011. Some Physical and Chemical Characteristics of Gilaburu (Viburnum Opulus L.) Fruits in Erzincan Region. Iğdır Üniversitesi Fen Bilimleri Enstitüsü Dergisi, 1(4): 9-14.

Rop O, Reznicek V, Valsikova M, Jurikova T, Mlcek J, Kramarova D 2010. Antioxidant Properties of European Cranberrybush Fruit (Viburnum opulus var. edule). Molecules, 15: 4467-4477.

Saltan G, Süntar I, Ozbilgin S, Ilhan M, Demirel MA, Oz BE, Keleş H, Akkol EK 2016. Viburnum opulus L.: A Remedy for the Treatment of Endometriosis Demonstrated by Rat Model of Surgically-İnduced Endometriosis. Journal of Ethnopharmacology, 193: 450-455.

Sarı̈zkan S, Türk G, Eken A, Bayram LÇ, Baldemir A, Doğan G 2017. Gilaburu (Viburnum opulus L.) Fruit Extract Alleviates Testis and Sperm Damages Induced by Taxane-Based Chemotherapeutics. Biomedicine \& Pharmacotherapy, 95: 1284-1294.

Taşkın O, İzli G, İzli N 2018. Convective Drying Kinetics and Quality Parameters of European Cranberrybush. Tarım Bilimleri Dergisi - Journal of Agricultural Sciences, 24(3): 349-358.

Tuglu D, Yilmaz E, Yuvanc E, Erguder I, Kisa U, Bal F, Batislam E 2014. Viburnum opulus: Could it be a new alternative, such as lemon juice, to pharmacological therapy in hypocitraturic stone 
patients?. Archivio Italiano di Urologia e Andrologia, 86(4): 297-299.

Ulger H, Ertekin T, Karaca O, Canoz O, Nisari M, Unur E, Elmalı F 2013. Influence of Gilaburu (Viburnum opulus) Juice on 1, 2-dimethylhydrazine (DMH)-induced Colon Cancer. Toxicology and Industrial Health, 29(9): 824-829.
Zarifikhosroshahi M 2015. Gilaburu (Viburnum Opulus L.) Meyvelerinde Biyoaktif, Biyokimyasal $\mathrm{Ve}$ Besin Element İçerıklerinin Belirlenmesi. Cukurova Üniversitesi Fen Bilimleri Enstitüsü Biyoteknoloji Anabilim Dalı Yüksek Lisans Tezi. $145 \mathrm{s.}$. 